\title{
Management of Angle's Class II Division 2 Malocclusion with Early Interceptive Orthodontics: A Case Report
}

\author{
Raj K Verma ${ }^{1}$, Satinder P Singh ${ }^{2}$, Sanjeev Verma ${ }^{3}$
}

\begin{abstract}
A case report to illustrate the early interceptive orthodontics for management of developing Class II Division 2 malocclusion is presented. A child with Angle's Class II Division 2 malocclusion was treated with prefunctional orthodontics, functional orthodontics followed by comprehensive orthodontics. Excellent results were achieved.

Keywords: Class II Division 2, Functional jaw orthopedics, Interceptive orthodontics.

Journal of Postgraduate Medicine, Education and Research (2022): 10.5005/jp-journals-10028-1556
\end{abstract}

\section{INTRODUCTION}

Early orthodontic treatment refers to orthodontic intervention before the eruption of permanent dentition (except third molars) is complete. ${ }^{\text {Th }}$ The treatment of children presenting with a Class II Division 1 malocclusion involves one of two approaches. The first provides treatment in two phases; one of intervention during the mixed dentition (phase I) followed by a second definitive course of appliance treatment in early adolescence (phase II). The second approach involves providing a single course of comprehensive therapy during adolescence. Early interceptive treatment is always indicated if the overbite is severe. Thus, if patient shows up with a deep impinging overbite, there is no doubt that it is the best time to treat a Class II Division 2 (Class II Div 2) malocclusion. ${ }^{2}$

A case report to illustrate the early Interceptive orthodontics for management of developing Class II Div 2 malocclusion is presented. This case is unique example to describe the importance of incisor correction at growing stage and achievement of mandibular correction in familial Class II malocclusion which could otherwise can lead to surgical treatment plan. This case report will add evidence for timely Class II correction after incisor proclination in growing patients.

\section{Clinical Findings}

A 10-year-old male patient reported to Oral Health Sciences Centre with chief complaint of unpleasant smile and irregular upper front teeth. The patient had positive familial history as his mother presented with Angle's Class II Div 1, father was Angle's Class II Div 2, and younger brother was also in distal step molar relationship. Extraoral examination revealed euryprosopic face, decreased lower anterior face height, convex facial profile, lower lip trap, and deep mentolabial sulcus (Fig. 1). On intraoral examination, the patient had mixed dentition with Class II molar relation, complete deep bite, retroclined central, and proclinedlateral incisors (Fig. 1).
${ }^{1-3}$ Oral Health Sciences Centre, PGIMER, Chandigarh, India

Corresponding Author: Sanjeev Verma, Oral Health Sciences Centre, PGIMER, Chandigarh, India, Phone: +91 9915946883, e-mail: drsanjuverma@yahoo.com

How to cite this article: Verma RK, Singh SP, Verma S. Management of Angle's Class II Division 2 Malocclusion with Early Interceptive Orthodontics: A Case Report. J Postgrad Med Edu Res 2022;56(1):41-46.

Source of support: $\mathrm{Nil}$

Conflict of interest: None

\section{Cephalometric Findings}

ANB angle 6 degrees, FMA 16 degrees, Upper Incisors to NA line 9 degrees, IMPA = 81 degrees.

Diagnosis: Skeletal Class II due to mandibular retrusion, hypo-divergent growth pattern, retroclined maxillary central incisors, and up-righted mandibular incisors (Fig. 2), (Table 1).

\section{Treatment Objective}

- Correction of inclination of anterior teeth,

- Correction of retrognathic mandible.

\section{Treatment Plan}

- Phase 1: Correction of inclination of central incisor and deep bite. Growth modulation for retro-positioned mandible.

- Phase 2: Fixed orthodontic treatment for final finishing and detailing, retention.

\section{Treatment Progress}

During phase 1 treatment, the inclination of retroclined maxillary incisors was corrected using double helical protraction wire ${ }^{3}$ (Fig. 3)

\footnotetext{
(c) The Author(s). 2022 Open Access This article is distributed under the terms of the Creative Commons Attribution 4.0 International License (https://creativecommons. org/licenses/by-nc/4.0/), which permits unrestricted use, distribution, and non-commercial reproduction in any medium, provided you give appropriate credit to the original author(s) and the source, provide a link to the Creative Commons license, and indicate if changes were made. The Creative Commons Public Domain Dedication waiver (http://creativecommons.org/publicdomain/zero/1.0/) applies to the data made available in this article, unless otherwise stated.
} 


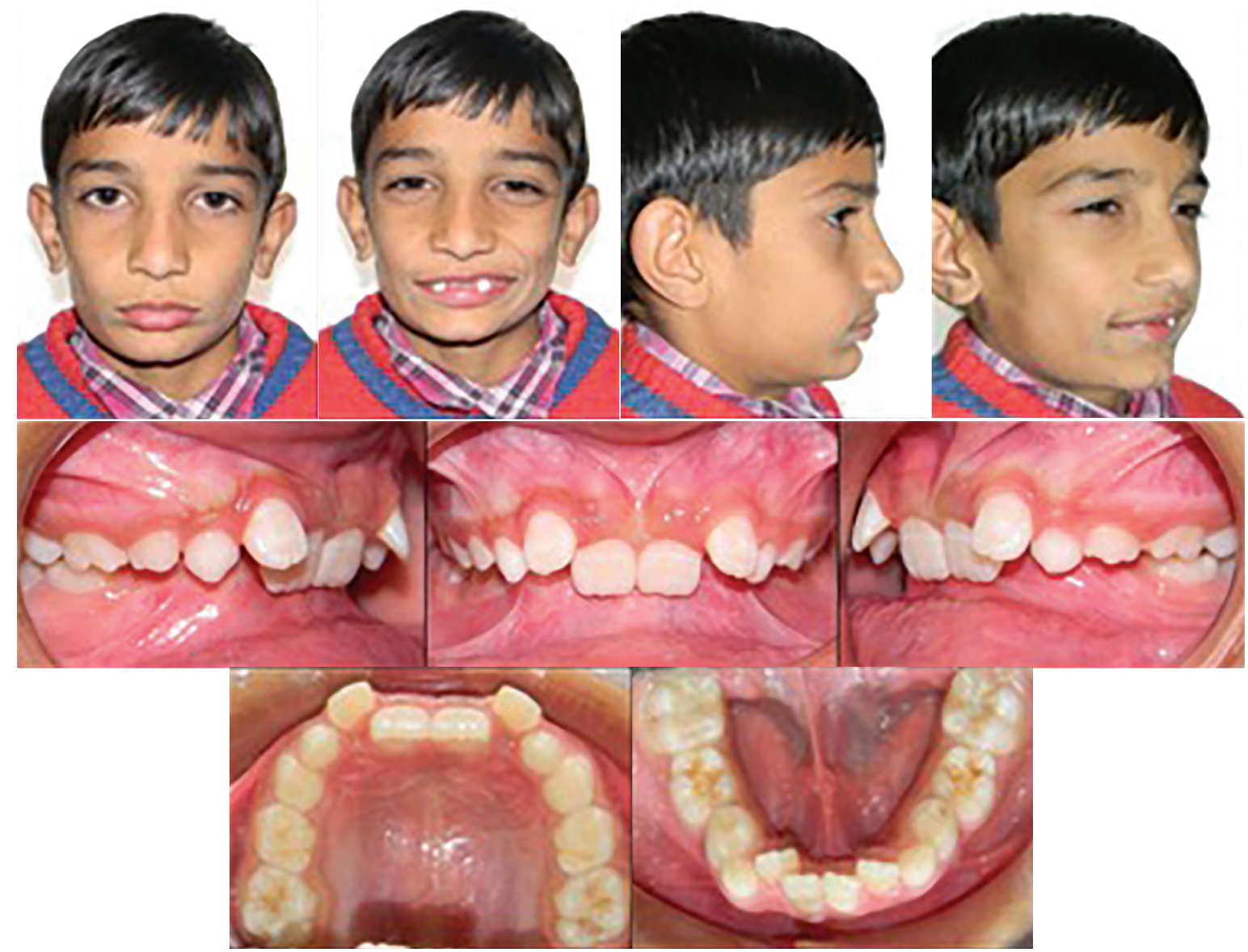

Fig. 1: Pretreatment extraoral and intraoral photographs

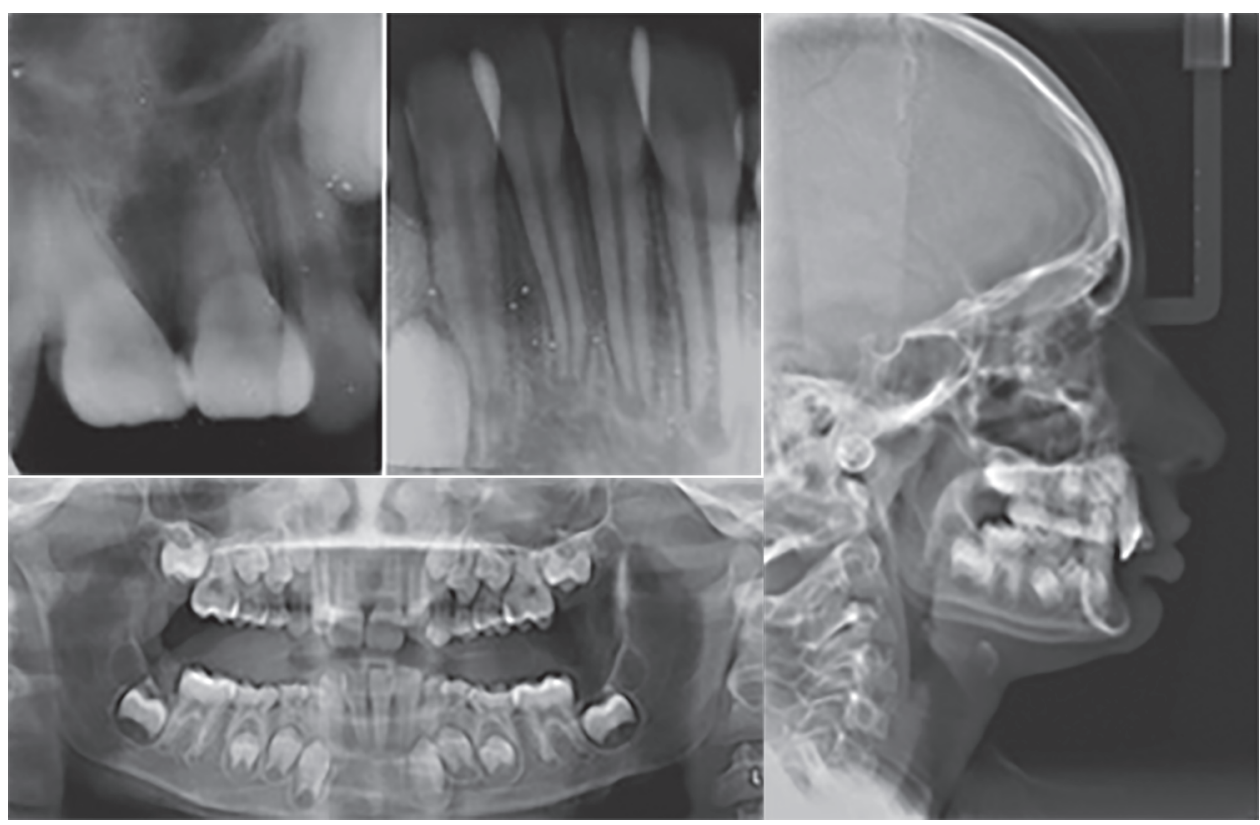

Fig. 2: Pretreatment radiographs 
Table 1: Comparison of pre- and posttreatment cephalometric parameters

\begin{tabular}{lccc} 
Cephalometric parameters & Pretreatment & Postfunctional & $75 \mathrm{~mm}$ \\
\hline SNA & $82^{\circ}$ & $83^{\circ}$ & $80^{\circ}$ \\
SNB & $76^{\circ}$ & $3^{\circ}$ & $84^{\circ}$ \\
ANB & $6^{\circ}$ & $20^{\circ}$ & $24^{\circ}$ \\
FMA & $16^{\circ}$ & $23^{\circ}$ & $28^{\circ}$ \\
U1 to NA & $9^{\circ}$ & $24^{\circ}$ & $31^{\circ}$ \\
L1 to NB & $0^{\circ}$ & $97^{\circ}$ & $106^{\circ}$ \\
IMPA & $81^{\circ}$ & $134^{\circ}$ & $119^{\circ}$ \\
Interincisal angle & $180^{\circ}$ & $-4 \mathrm{~mm}$ & $-5.5 \mathrm{~mm}$ \\
E-line to upper lip & $-1.5 \mathrm{~mm}$ & $-2 \mathrm{~mm}$ & $-2.5 \mathrm{~mm}$ \\
E-lip to lower lip & $1 \mathrm{~mm}$ & &
\end{tabular}

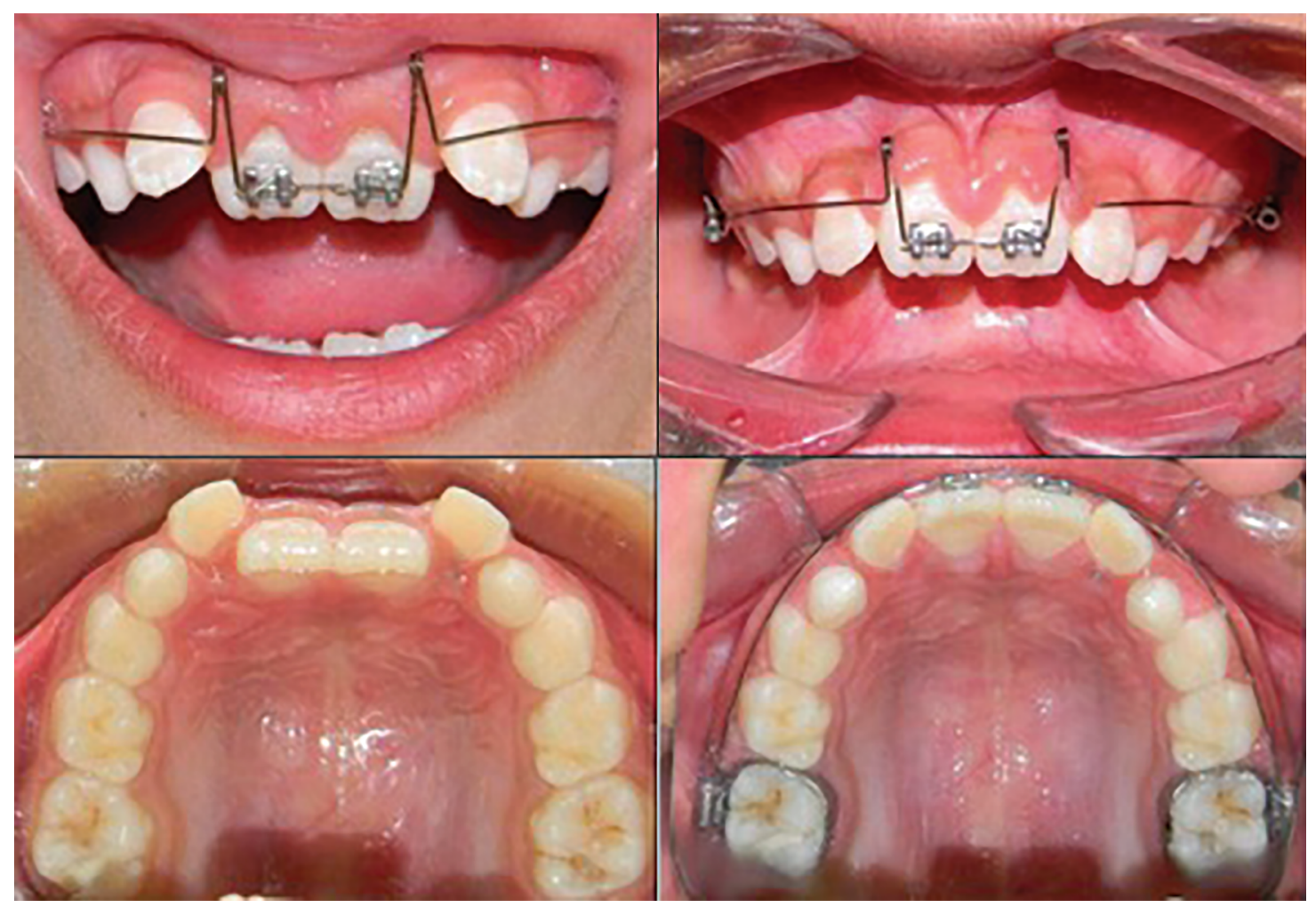

Fig. 3: Double helical protraction wire for correction of retroclined incisors 
and mandibular advancement by functional (twin block appliance) (Fig. 4). Twin block appliance therapy was continued for 2.6 years followed by fixed orthodontic treatment. In phase 2 treatment, fixed multibracket therapy was used for final finishing and detailing in both upper and lower arches. The functional appliance correction of skeletal class II was retained using Class II elastics. Total treatment duration was 4 years 6 months. The stage and posttreatment extraoral photographs show marked improvement in profile (Fig. 5). The stage and posttreatment intraoral photographs show satisfactory occlusion with Class I molar relation and normal overjet and overbite (Fig. 6). Cephalometric findings show correction skeletal Class II to Class I malocclusion with improvement of ANB from 6-2 degrees. The inclination of maxillary incisors also improved to 28 degrees to NA line. IMPA increased to 106 degrees (Table 1). Lateral cephalograms and their superimpositions during treatment progress showed marked growth of mandible (Figs 7 to 9).

\section{Discussion}

Main objective of early interceptive orthodontics is to correct upper incisor retroclination and to provide an oral environment that is favorable for normal mandibular growth. Double helical protraction wire was used to procline incisors as there was sufficient space for the proclination of the central incisors. Early correction of central incisor inclination followed by functional appliance therapy to correct mandibular retrusion helped successful treatment of patient. ${ }^{5,6}$ Functional appliances reposition the mandible forward and help in management of mandibular retrusion in growing children. ${ }^{4}$ Normal profile, harmonious skeletal, and dental relations were achieved. IMPA was increased as expected after twin block therapy.

\section{Conclusion}

Treatment of Class II Div 2 malocclusion in growing patients requires a careful diagnosis and treatment planning and early interceptive orthodontics is very important for successful management of these cases. It is very important for the clinicians to see the signs of Div 2 malocclusion and refer them to appropriate centre for their early diagnosis and interception. Early interception provides opportunity of nonsurgical treatment for mandibular deficiency which could otherwise lead to an ortho-surgical treatment plan.

Primary take away from case report is that early diagnosis and timely management of retroclined incisors in Div 2 cases are main requisite in interventional orthodontics.
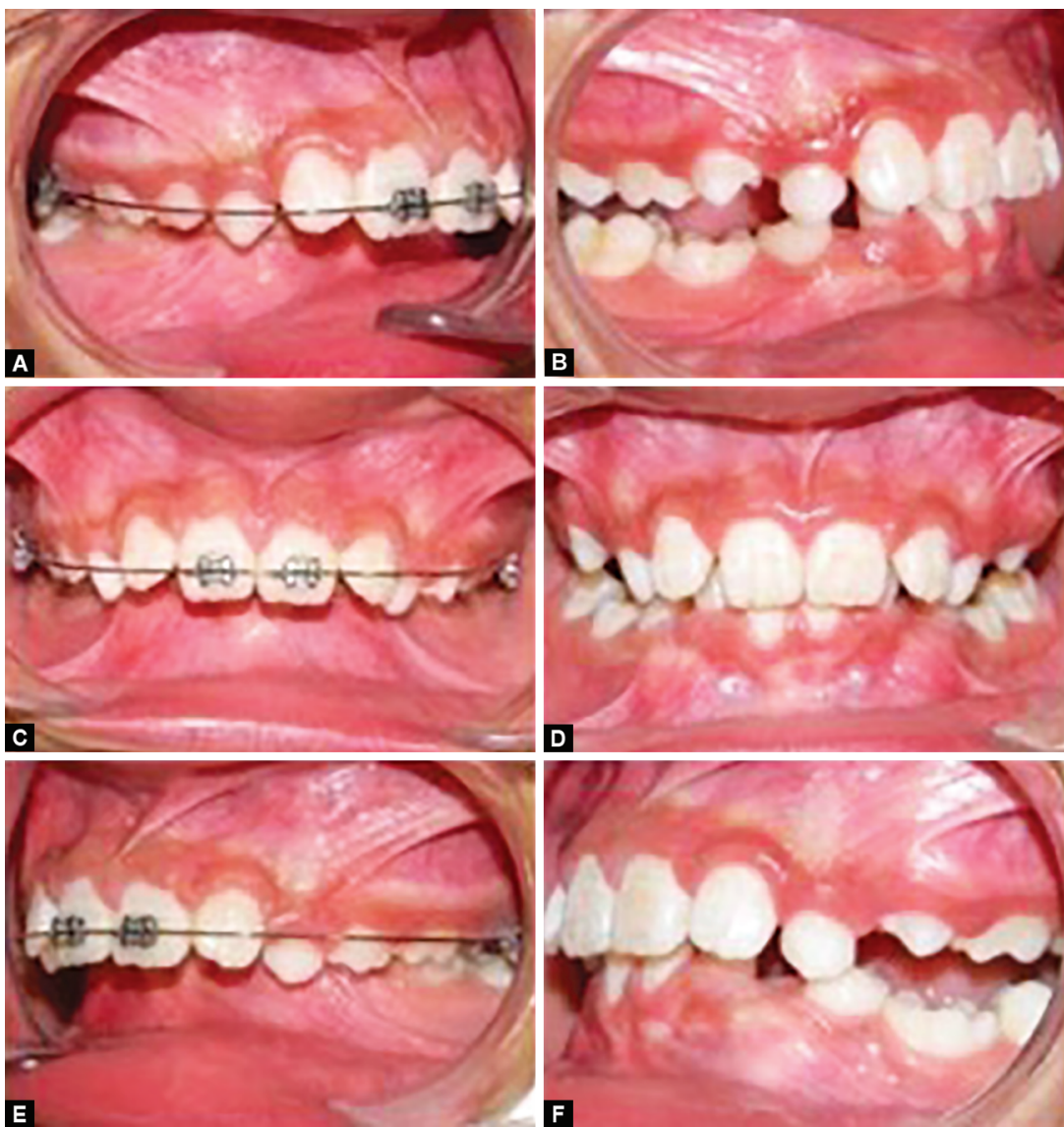

Fig. 4: Intraoral: Pre- and post-functional photographs 


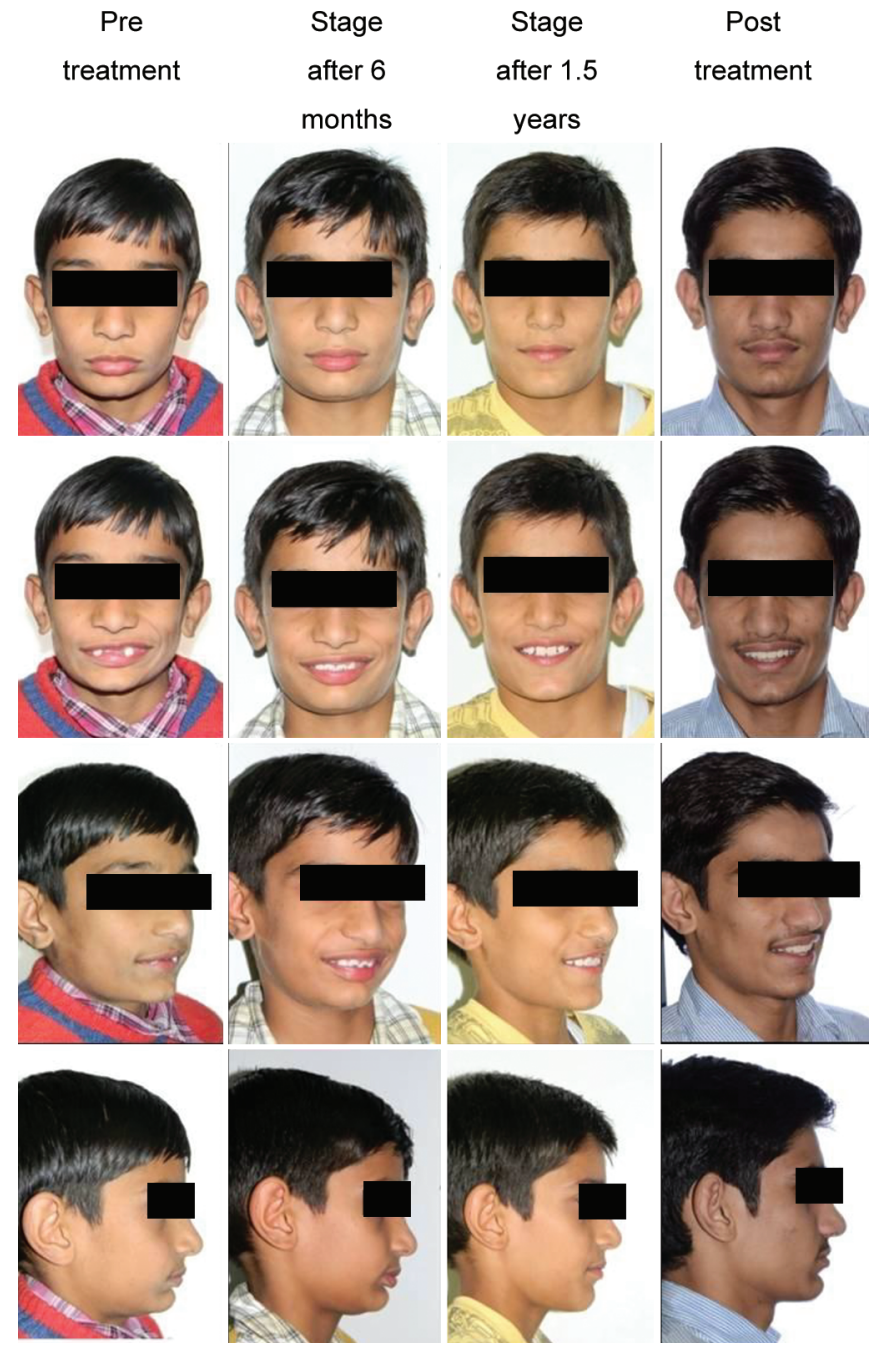

Fig. 5: Extraoral: Pretreatment, stage, and posttreatment photographs
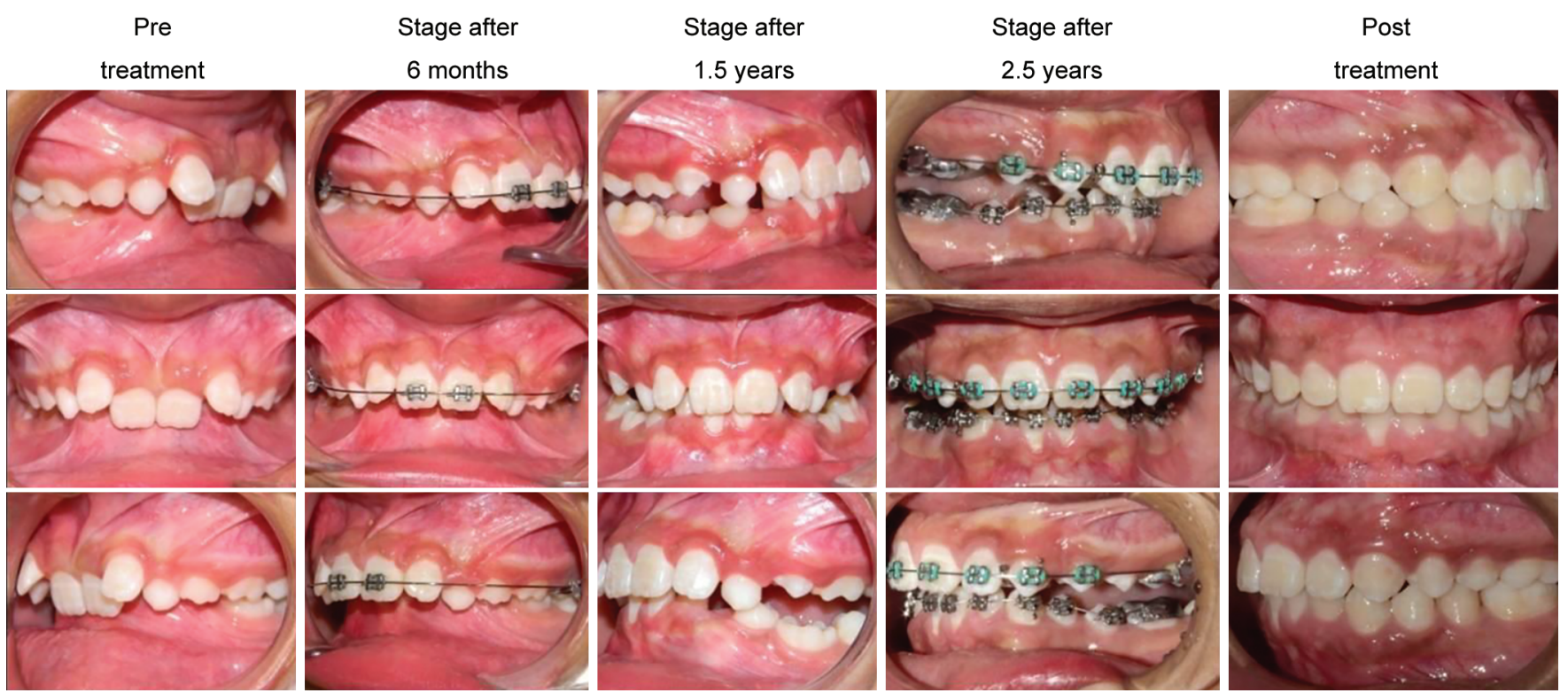

Fig. 6: Intraoral: Pretreatment, stage, and posttreatment photographs 

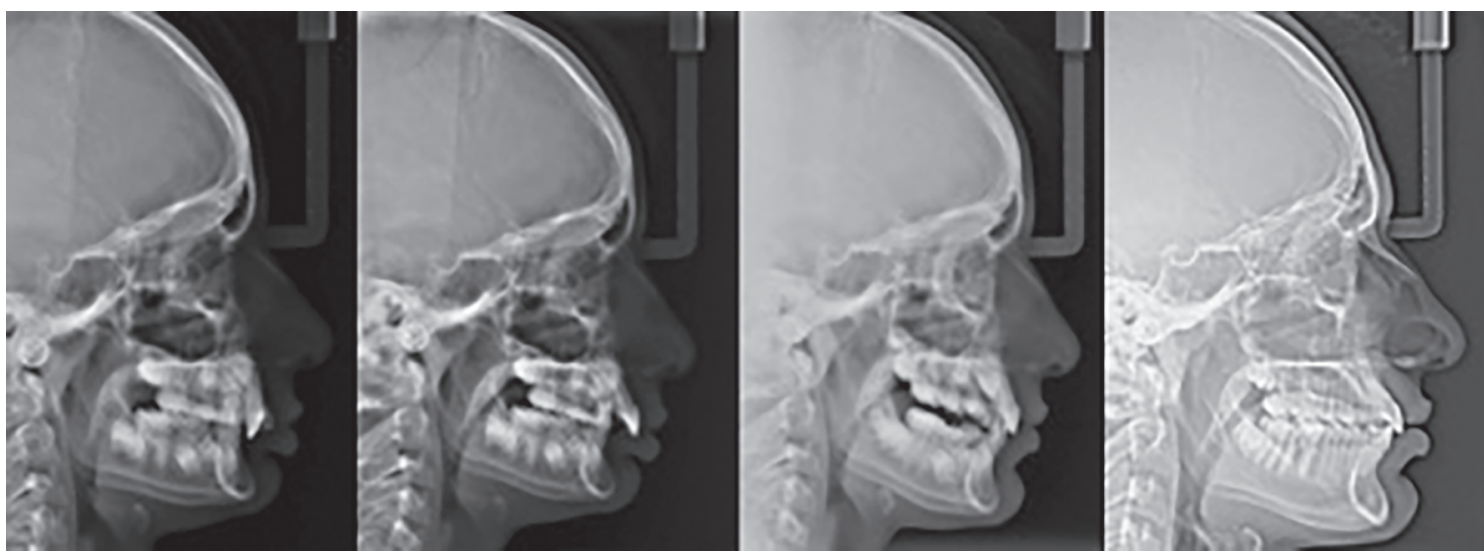

Fig. 7: Lateral cephalograms: Pretreatment, stage, and posttreatment

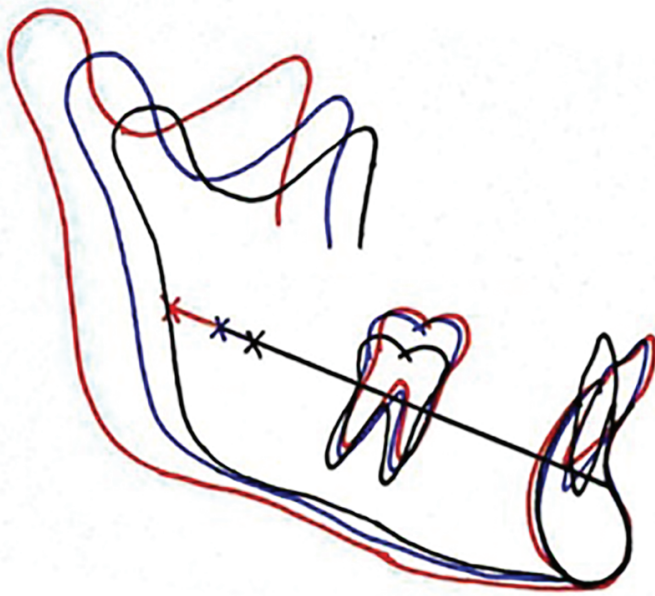

Fig. 8: Cephalometric superimposition: Mandibular: Pretreatment (black), stage 1.5 years blue), and posttreatment (red)

\section{References}

1. Orthodontics: Current principles and techniques, sixth edition. Graber LW, Vanarsdall RL, Vig KWL, Huang GJ. Part 3, Chapter 16, 403-433.

2. Mathews JR. Interception of class II malocclusion. Angle Orthod 1971;41(2):81-99. DOI: 10.1043/0003-3219(1971)041<0081:IO $\mathrm{CIM}>2.0 . \mathrm{CO} ; 2$

3. Verma RK, Jena AK, Singh SP, et al. Innovative approach to class II malocclusion. Pediatr Dent 2014;43-47.

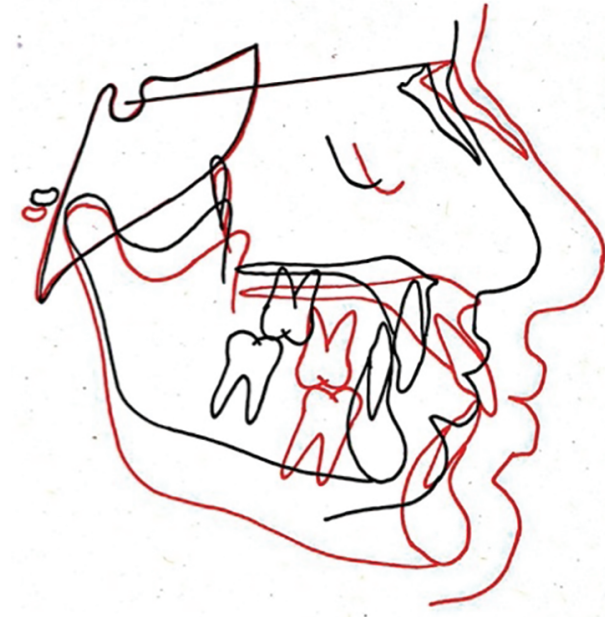

Fig. 9: Cephalometric superimposition: Pretreatment (black) and posttreatment (red)

4. Clark, WJ. (1995). Twin block functional therapy: applications in dentofacial orthopaedics. London: Mosby-Wolfe.

5. Baccetti T, Franchi L, McNamara JA, et al. Early dentofacial features of class II malocclusion: a longitudinal study from the deciduous through the mixed dentition. Am J Orthod Dentofacial Orthop 1997;111(5):502-509. DOI: 10.1016/s0889-5406(97)70287-7

6. McNamara JA. Components of class II malocclusion in children 8-10 years of age. Angle Orthod 1981;51(3):177-202. DOI: 10.1043/0003-3219(1981)051<0177:COCIMI>2.0.CO;2 